\title{
Contradições do experimento neoliberal do Porto Maravilha no Rio de Janeiro
}

\author{
Contradictions of the Porto Maravilha neoliberal experiment in Rio de Janeiro \\ Orlando Santos Junior ${ }^{1}$, Mariana Werneck ${ }^{1}$, Patricia Ramos Novaes ${ }^{1}$ \\ ${ }^{1}$ Universidad Federal de Río de Janeiro, Rio de Janeiro, Brasil \\ orlando.santosjr@gmail.com
}

\section{Resumen}

O objetivo do artigo é levantar algumas teses ou argumentos sobre as especificidades da neoliberalização da cidade do Rio de Janeiro, tomando o caso da renovação do Porto Maravilha, que também podem contribuir para a compreensão do contexto urbano brasileiro e latino-americano. Os resultados da análise desenvolvida possibilitam interpretar as contradições associadas à implementação do projeto de renovação do Porto Maravilha em torno de três teses. A primeira afirma que a compreensão das transformações urbanas no Porto Maravilha deve levar em consideração as características específicas da configuração urbana da cidade - uma ordem urbana híbrida, desigual e combinada -, e do papel da cultura negra e da diáspora africana na sua configuração. A segunda tese argumenta que o Porto Maravilha se constitui em um experimento neoliberal deflagrado por uma coalizão de interesses, mas que sua implementação é constrangida pela ordem urbana híbrida, desigual e combinada e, ao mesmo tempo, a modifica, num processo de destruição criativa multiescalar que produz uma versão local de um fenômeno global. A terceira tese argumenta que os projetos de renovação urbana no Rio de Janeiro promovem um tipo particular de elitização, a gentrificação periférica, caracterizada por processos de branqueamento e tentativas de aniquilação da cultura negra, mas as resistências sociais resultam na reprodução da ordem urbana híbrida, desigual e combinada. Em termos de métodos e técnicas aplicados, a pesquisa envolveu a combinação de diferentes técnicas de coletas de dados, destacando-se a análise documental e as observações direta e participante.

Palavras-chave: Diáspora Africana, Gentrificação Periférica, Urbanização Neoliberal, Ordem Urbana, Porto Maravilha.

\begin{abstract}
This paper aims to raise some theses or arguments about the specificities of the neoliberalization process in the city of Rio de Janeiro, which may also contribute to the understanding of the Brazilian and Latin American urban context. Results allow the development of three thesis about the contradictions surrounding Porto Maravilha renewal project. The first one states that the understanding of urban transformations in Porto Maravilha must consider the specific characteristics of the urban configuration of the city (a hybrid, unequal and combined urban order), such as the role of black culture and the African diaspora in its configuration. The second thesis argues that Porto Maravilha constitutes a neoliberal experiment triggered by a coalition of interests, but, at the same time, its implementation is constrained by the hybrid, unequal and combined urban order - which the first modifies in a process of multiscale creative destruction that produces a local version of a global phenomenon. The third thesis argues that urban renewal projects in Rio de Janeiro promote a kind of elitization, peripheral gentrification, characterized by whitewashing processes and attempts to annihilate black culture. Social resistances, however, result in the reproduction of the hybrid urban order, uneven and combined. Research involved several data collection techniques, specially, documental analysis and direct observation.
\end{abstract}

Keywords: African diaspora, Neoliberal urbanization, Peripheral gentrification, Porto Maravilha, Urban order.

Documento recibido el 29 de agosto de 2019 y aceptado el 13 de abril de 2020.

Este artículo participó en el Seminario Internacional "El Complejo Urbano Financiero-Inmobiliario en América Latina", realizado el jueves 4 y viernes 5 de abril de 2019, en Santiago de Chile, organizado y patrocinado en el marco del Proyecto Fondecyt Regular 1151287 - Investigador Principal: Ernesto López Morales, el Centro de Estudios del Conflicto y la Cohesión Social (COES), la Facultad de Arquitectura y Urbanismo de la Universidad de Chile y su Doctorado en Territorio, Espacio y Sociedad (D_TES).

Cómo citar: Santos Junior, O., Werneck, M. e Ramos Novaes, P. (2020). Contradições do experimento neoliberal do Porto Maravilha no Rio de Janeiro. Revista de Urbanismo, 42, 1-16. https://doi.org/10.5354/0717-5051.2019.54265 
Nas últimas décadas, mudanças no padrão de governança urbana promoveram diversos ajustes e reestruturações socioespaciais na cidade do Rio de Janeiro, por meio de experimentos neoliberais em áreas específicas, entre as quais se destaca a região portuária, onde se desenvolve o projeto de renovação urbana denominado Porto Maravilha. De fato, esse fenômeno não é restrito a cidade do Rio de Janeiro, nem as cidades brasileiras, mas atinge diversas cidades latino-americana.

Esses ajustes têm sido caracterizados por diversas dinâmicas vinculadas à difusão do neoliberalismo em escala planetária (Harvey, 2008), entre as quais destacamse: (i) a destruição/criação de estruturas urbanas, instituições de gestão, marcos regulatórios e representações simbólica pró-mercado, o que Theodore, Peck e Brenner (2009) descrevem como urbanização neoliberal; (ii) a mobilização, por coalizões de poder, de processos de produção da cidade como "máquina de crescimento" (Logan e Molotch, 1987), voltadas para a promoção dos negócios urbanos (Arantes, 2000; Ferreira 2003); e (iii) promoção de processos de gentrificação e elitização de certos espaços das cidades, notadamente suas áreas centrais (Smith, 2006), associados à ressignificação simbólica e à mudanças nas formas de apropriação desses lugares, seja pela mudança no perfil dos serviços ofertados e da população usuária dos mesmos, seja no perfil dos novos moradores.

A reflexão proposta parte da compreensão de que as transformações espaciais contemporâneas decorrentes do desenvolvimento geográfico desigual, sob o neoliberalismo, requer levar em consideração a interação entre os processos de acumulação de capital em escala global e os processos sociopolíticos específicos de cada localidade, resultando em modalidades específicas de neoliberalização (Brenner \& Theodore, 2002; Brenner, Peck \& Theodore, 2009). O objetivo do artigo é discutir sobre as especificidades dos experimentos de neoliberalização da cidade do Rio de Janeiro, a partir do caso da Operação Urbana Porto Maravilha, que também podem contribuir para a compreensão do contexto urbano brasileiro e latino-americano.

A reflexão proposta está orientada pelas seguintes questões: (i) De que maneira se expressa a urbanização neoliberal na cidade do Rio de Janeiro e na sua zona portuária? (ii) Como a implantação deste megaprojeto se relaciona com a historicidade e com a cultura afrodescendente existente na zona portuária? (iii) Em que medida existem processos de gentrificação associados a este projeto e quais suas características? e (iv) Em que consiste o conceito de Gentrificação Periférica?

\section{Metodologia}

A análise empreendida neste artigo adota como referência a teoria crítica, e em especial, a teoria critica urbana (Brenner, 2010). Isso implica em uma abordagem relacional, na qual, como argumentam Alhes-Mazzotti e Gewandsznajder:

procura-se investigar o que ocorre nos grupos e instituições relacionando as ações humanas com a cultura e as estruturas sociais e políticas, tentando compreender como as redes de poder são produzidas, mediadas e transformadas. (2004, p. 139)

No que se refere à problemática, a análise assume um caráter exploratório ou ensaístico, não envolvendo a comprovação empírica de teorias sobre a relação entre variáveis vinculadas aos eventos e processos sociais aqui considerados. Pelo contrário, busca-se explorar novas possibilidades interpretativas e abordagens conceituais, colocando em relação teorias, historicidade, culturas e os processos sociais analisados. Nesta direção, também assumimos uma perspectiva decolonial, na medida em que buscamos adotar criticamente as teorias formuladas no contexto dos países centrais, levando em consideração as especificidades dos processos sociais do Brasil e dos países periféricos (Miglievich-Ribeiro, 2014).

Em termos de métodos e técnicas aplicados, a pesquisa envolveu a combinação de diferentes técnicas de coletas de dados, destacando-se a análise documental e as observações direta e participante. A análise documental envolveu o levantamento de documentos institucionais e leis municipais, estaduais e federais, além de fontes na imprensa. A observação direta e participante foi desenvolvida principalmente nos seguintes âmbitos: (i) em espaços públicos de participação, envolvendo as audiências públicas promovidas pela Prefeitura Municipal do Rio de Janeiro para discutir o projeto de habitação de interesse social da região portuária e reuniões solicitadas pelos pesquisadores com a presidência da Companhia de Desenvolvimento Urbano da Região do Porto do Rio de 
Janeiro (CDURP); (ii) em visitas a área de estudo, envolvendo toda a região, em especial as obras implementadas pelo projeto, os empreendimentos imobiliários em curso ou já implementados, e as ocupações urbanas promovidas pelos movimentos de moradia; e (iii) reuniões com organizações e movimentos sociais, envolvendo tanto organizações sociais presentes no território quanto movimentos sociais da cidade do Rio de Janeiro que atuam na área portuária.

Cabe destacar que apesar de se constituir em um estudo de caso, esta foi desenvolvida no âmbito de uma rede de nacional de pesquisa, o Observatório das Metrópoles, o que permitiu a sistemática e virtuosa interlocução com outras pesquisas sobre a grandes projetos urbanos e renovação urbana de áreas centrais, que adoram referenciais teóricos e metodologias similares.

Com a abordagem teórica e os métodos de pesquisa adotados buscamos superar o dilema sociológico, tão bem por lembrado por Bourdieu, Chamboredon e Passeron (2004, p. 50) de "tratar diferentemente o idêntico e de uma forma idêntica o diferente, comparar o incomparável e deixar de comparar o comparável", sem esquecer que "os fatos não falam", e que mesmo os dados mais objetivos são produzidos e interpretados a luz de pressupostos teóricos (Bourdieu, Chamboredon e Passeron, 2004).

\section{Discussão e resultados: A Operação Urbana do Porto Maravilha entre trancos e barrancos}

A região portuária é palco de uma das maiores intervenções em curso na cidade, a Operação Urbana Consorciada da Área de Especial Interesse Urbanístico da Região Portuária do Rio de Janeiro, também conhecida como Operação Urbana Consorciada (OUC) Porto Maravilha, criada em 2009 (Leis Municipais 101 e 102, de 2009). A Operação Urbana abrange 5 milhões de $\mathrm{m}^{2}$ envolvendo uma área contígua situada no centro da Cidade do Rio de Janeiro, no Brasil, bastante desvalorizada economicamente, mas com grande potencial de valorização para o capital imobiliário tendo em vista sua localização estratégica próxima ao seu centro financeiro CBD - Central Business District (Figura 1).

Figura 1

A Operação Urbana Consorciada do Porto Maravilha na Cidade do Rio de Janeiro, Brasil.

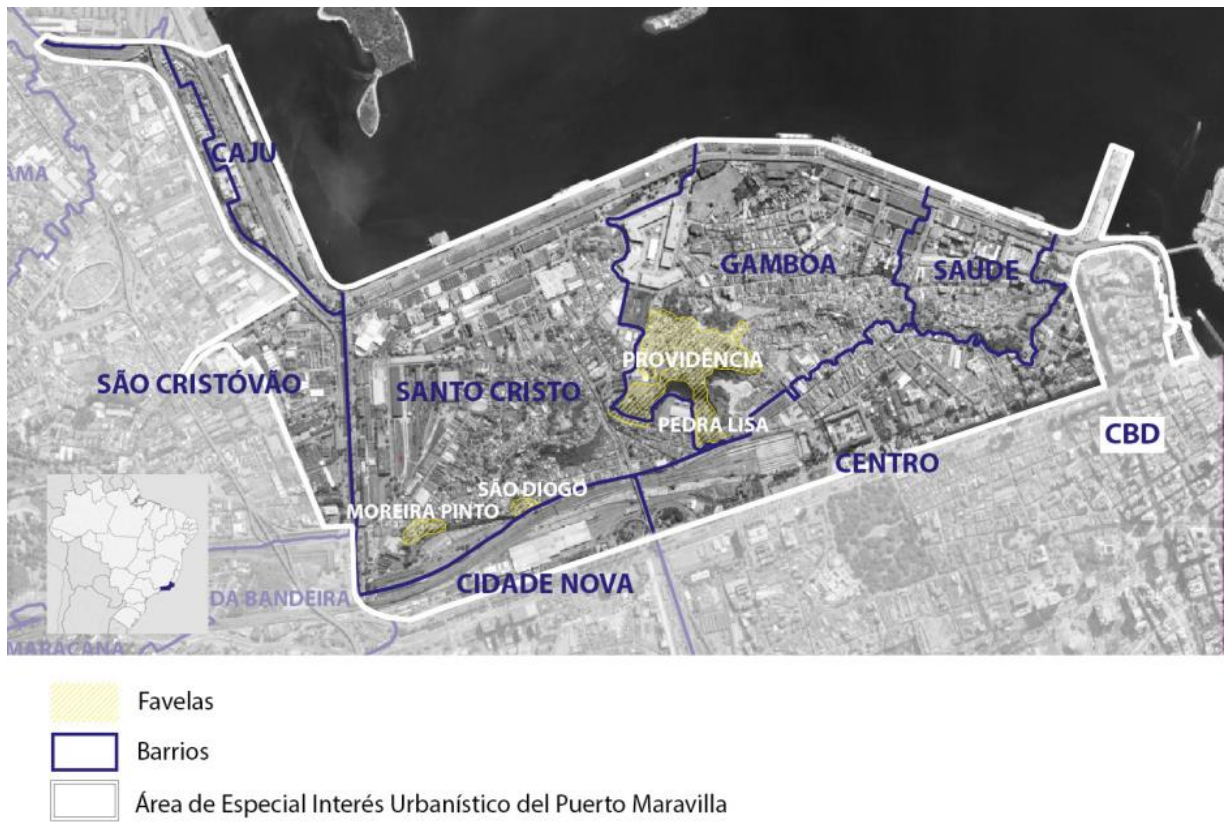

Fuente: Werneck, 2016. 
Para se entender o contexto de criação deste projeto de renovação urbana, é preciso levar e conta que a região portuária, desde os meados do século $X X$, vinha sofrendo uma reconfiguração urbana com a queda de investimentos do poder público. Paralelamente e progressivamente, a região passou a ser ocupada majoritariamente por estratos de baixa renda, que sempre estiveram presentes na área. ${ }^{1}$

Neste processo de escassez de investimento em infraestrutura urbana, viu-se a expansão de habitações informais e a desvalorização de parte dessa área central da cidade. Ao mesmo tempo, a partir da década de 1980, são implementadas diversas políticas visando a preservação histórico-cultural do centro da cidade, onde destacam-se a criação da Zona Especial do Corredor Cultural, de "preservação paisagística e ambiental do Centro da Cidade do Rio de Janeiro" (lei municipal 506, de 1984) e a criação da Área de Proteção Ambiental dos bairros de Saúde, Gamboa e Santo Cristo (APA SAGAS / Lei no 971, de 1987), situados na zona portuária. Posteriormente, com a edição do primeiro Plano Diretor Decenal da cidade, em 1992, as APAs passam a ser denominadas de APACs - Áreas de Proteção do Ambiente Cultural.

Especialmente a partir dos anos 1970, diante do quadro de empobrecimento da população local e desinvestimento em termos de políticas públicas, crescentemente é difundida a imagem de área vazia, abandonada, degradada e decadente, tanto nos discursos oficiais do poder público como no da mídia (Pio, 2014), o que justificaria a necessidade de uma "revitalização" urbana. Tal fato levou a uma série de tentativas, entre os

\footnotetext{
${ }^{1}$ A zona portuária foi a maior porta de entrada do tráfico de escravos negros no Brasil e apesar da sua localização privilegiada, desde muito cedo foi ocupada pelas classes populares.

${ }^{2}$ Entre as principais obras previstas na operação urbana, destacam-se as seguintes construções e intervenções: Museu de Arte do Rio (MAR), Museu do Amanhã, Via Binário do Porto, Túnel Rio 450, Via Expressa e Túnel Prefeito Marcello Alencar, Nova Orla Conde, o VLT do Centro Veículo Leve Sobre Trilhos, $70 \mathrm{~km}$ de vias reurbanizadas, $650.000 \mathrm{~m}^{2}$ de calçadas refeitas, $700 \mathrm{~km}$ de redes de infraestrutura urbana reconstruídas (água, esgoto, drenagem), $17 \mathrm{~km}$ de novas ciclovias, demolição do elevado da Perimetral e plantação de 15.000 árvores.
}

${ }^{3}$ A OUC Porto Maravilha envolve os bairros da Saúde, Gamboa e Santo Cristo, trechos dos bairros do Centro, Caju, Cidade Nova e São Cristóvão, anos de 1980 e 1990, de elaboração de projetos de requalificação ou renovação urbana da região, mas por inúmeros motivos esses projetos não ganharam fôlego (Diniz, 2013).

No entanto, em 2009 foi lançada a Operação Urbana Consorciada do Porto Maravilha. Neste projeto de renovação urbana, que abrange 5 milhões de metros quadrados, são implementadas ações relacionadas à modernização da infraestrutura urbana, saneamento ambiental, redes de informática e telecomunicações, entre outros serviços ${ }^{2}$, numa área que envolve integralmente os bairros da região portuária e o entorno do centro da cidade. ${ }^{3}$ Vale destacar que, dentro da área da operação urbana, aproximadamente 3,8 milhões de $\mathrm{m}^{2}$ fazem parte da APAC do Projeto SAGAS, o que coloca diversas restrições à demolição de imóveis históricos e restringe a ampliação do gabarito construtivo no perímetro por ela definido. Em 2010, com base nos dados do Censo (IBGE), a população total residente na área da Operação Urbana era de 29.953 pessoas, cujo perfil socioeconômico pode ser caracterizado como de baixa e média renda 4 , sendo 4.354 moradores do morro da Providência, onde surgiu a primeira favela do país.

Estruturada a partir da mercantilização de terras públicas, da criação e venda de potencial construtivo e da instituição de uma parceria público-privada, a complexa engenharia institucional da Operação Urbana Consorciada (Werneck, 2016) pode ser sintetizada da seguinte forma:

1. A criação de uma companhia municipal, a Companhia de Desenvolvimento Urbano da Região do Porto do Rio de Janeiro (CDURP) ${ }^{5}$, responsável pela gestão da

\footnotetext{
e as favelas da Providência, Pedra Lisa, Moreira Pinto e São Diogo, além do Morro da Conceição e do Morro do Pinto.

${ }^{4}$ Segundo a faixa de renda, aproximadamente $6 \%$ dos domicílios particulares permanentes - DPPs não possuem renda domiciliar, cerca de $88 \%$ possuem renda familiar entre 0 e 3 salários mínimos e outros $6 \%$ possuem renda familiar maior que 3 salários mínimos (Instituto Pereira Passos, 2016).

${ }^{5}$ Conforme o Estatuto Social da empresa, a CDURP é "uma sociedade de economia mista, constituída sob a forma de sociedade anônima, com personalidade jurídica de direito privado e patrimônio próprio, cujo controle será exercido pelo Município do Rio de Janeiro". O controle do Município é exercido por meio "da manutenção pelo Município, direta ou indiretamente, de, no mínimo, cinquenta por cento, mais uma ação, do capital votante da CDURP" (Prefeitura do Rio de Janeiro, 2017).
} 
Operação Urbana Consorciada Porto Maravilha. A criação da empresa é um dos aspectos fundamentais da estrutura financeira da operação porque permite à CDURP gerir os ativos patrimoniais transferidos a ela pelo Município e permite sua participação, como quotista, em fundos de investimento ou fundos garantidores de obrigações pecuniárias. Ambas prerrogativas são fundamentais para facilitar os processos de privatização dos terrenos públicos e as negociações com os investidores privados.

2. A instituição de uma parceria público-privada (PPP) visando a realização das obras de infraestrutura e a gestão de serviços previstos na operação urbana ${ }^{6}$. A PPP foi vencida, em licitação pública, pelo Consórcio Porto Novo, integrado pelas empresas Odebrecht Infraestrutura (37,5\%), OAS $(37,5 \%)$ e Carioca Engenharia (25\%), todas grandes empreiteiras nacionais. A execução das obras do Porto Maravilha se realiza através da maior Parceria Público-Privada (PPP) do Brasil, no valor de $\mathrm{R} \$ 7,6$ bilhões. $O$ contrato de PPP foi assinado em novembro de 2010 entre a CDURP e a concessionária vencedora da licitação pública, a Porto Novo S/A, concedendo a administração da região por 15 anos, por regime de concessão administrativa, dos serviços e obras de revitalização, operação e manutenção da Área de Especial Interesse Urbanístico da Região do Porto do Rio de Janeiro, incluindo a gestão de serviços públicos como limpeza, iluminação, sistema viário e saneamento básico.

3. A criação e venda de potencial construtivo para financiar o pagamento da parceria público-privada. Ou seja, para construir um determinado número de pavimentos em um setor (a área portuária é dividida em espaços denominados setores), é necessário comprar potencial construtivo, o que permite ao proprietário ou incorporador, construir determinado número de pavimentos. No caso da Operação Urbana do Porto Maravilha, o potencial projetado é de 4 milhões de $\mathrm{m}^{2}$ de área construída sobre 1 milhão de $\mathrm{m}^{2}$ em terrenos que podem abrigar novas edificações. $A$ venda de potencial construtivo é realizada por meio da emissão de títulos, os Certificados de Potencial Adicional de Construção - $\mathrm{CEPACs}^{7}$, que são comercializados no mercado.

4. A valorização fundiária, de forma que a venda dos CEPACs possa efetivamente cobrir os custos do empreendimento, tendo em vista que seu valor inicial era inferior ao valor do contrato da PPP, ou seja, das obras e serviços previstos pela Operação Urbana. Isso implica ressignificar a imagem da área portuária superando sua imagem de espaço degradado e decadente, fortemente associada à pobreza, prostituição e marginalidade, e investir em novo artefatos simbólicos associados à modernidade. Daí a importância do investimento nos novos museus construídos na região, o Museu do Amanhã e o Museu de Arte do Rio (MAR).

5. A privatização dos terrenos públicos na região portuária, buscando criar o mercado de terras com potencial de consumir os CEPACs, tendo em vista que a maior parte da área passível de consumir potencial construtivo era de propriedade pública, em geral terras da União. Esse cenário demandava uma difícil negociação envolvendo o governo federal, por meio da Secretaria de Patrimônio da União, e o Município, de forma a negociar os processos de transferência do patrimônio público para o mercado (Santos Junior, Werneck, Borba e Carvalho, 2019).

A criação de um mercado de comercialização do potencial construtivo. Os CEPACs são títulos comercializados na bolsa de valores não atrelados a um

\footnotetext{
7 Os Certificados de Potencial Adicional de Construção - CEPAC - se constituem em uma modalidade de outorga onerosa do direito de construir, instituído pelo Estatuto da Cidade (Lei Federal no 10.257/2001), que pode ser adotado pelas administrações municipais brasileiras na gestão do solo urbano. Por este instrumento, o poder público municipal pode estabelecer um índice de aproveitamento do terreno igual a um (no qual a área total edificada deve ser igual a área do terreno) e gabaritos de construção superiores a este índice, por setores em determinada área, e consentir a exploração desses gabaritos em troca do pagamento efetuado pelos proprietários do solo.
} 
terreno específico, permitindo ao investidor comprá-los com objetivos especulativos, buscando ganhos decorrentes da sua valorização. O incorporador ou proprietário que desejar construir e investir em empreendimentos residenciais ou corporativos deverá vincular os CEPACs a um terreno específico situado em um dos setores da área portuária que compõe a operação urbana.

Na OUC Porto Maravilha, todo o potencial construtivo, os CEPACs, foi comprado, de uma só vez, por um fundo paraestatal, o Fundo de Garantia por Tempo de Serviço (FGTS), gerido por um banco público, a Caixa Econômica Federal.

Cabe apontar que o Fundo de Garantia do Tempo de Serviço (FGTS) foi criado, em 1966, com o objetivo de proteger o trabalhador demitido sem justa causa, mediante a abertura de uma conta vinculada ao contrato de trabalho, gerida pelo banco federal CEF - Caixa Economica Federal. No início de cada mês, os empregadores depositam em contas bancárias dos empregados, abertas na CEF, o valor correspondente a $8 \%$ do salário de cada funcionário. O FGTS é constituído pelo total desses depósitos mensais e os recursos pertencem aos trabalhadores empregados que, em algumas situações específicas previstas em lei, podem utilizar os recursos depositados nas suas contas.

A aquisição de títulos pelo fundo público possibilitou a realização do projeto de revitalização da área urbana carioca, garantindo os recursos necessários ao pagamento da parceria público-privada. Ao mesmo tempo, a participação do FGTS previa o retorno dos investimentos por meio da revenda dos títulos de potencial construtivo ao mercado imobiliário e da valorização fundiária prometida (Werneck et al, 2018).

Os CEPACs constituíam-se, portanto, no combustível do modelo econômico instituído para o Porto Maravilha, e ele afeta de forma diferenciada os setores da área portuária, em razão do potencial construtivo permitido em cada setor.

Esta modelagem financeira compromete os objetivos da OUC Porto Maravilha: anunciada sob o argumento de privilegiar o transporte coletivo, preservar o patrimônio histórico e cultural da região e promover medidas de proteção e manutenção da população residente, o projeto revestia-se do interesse público. Todavia, a lógica de financiamento da operação urbana consorciada subordina a execução do projeto aos interesses do mercado e dos investidores privados, seguindo as diretrizes de governança empreendedorista neoliberal (Harvey, 2005).

Ou seja, os gestores devem tomar decisões favoráveis aos interesses do mercado, em um processo que pode ser interpretado como a tentativa de empreender a cidade para promover os negócios urbanos, ou seja, tratando a cidade como uma máquina de crescimento (Cardoso, 2013; Logan e Molotch, 1987).

Além disso, os fortes investimentos no patrimônio histórico e cultural e na construção de artefatos culturais marcadamente pós-modernos expressam a intencionalidade de ressignificação simbólica da região, buscando atrair novos consumidores de classe média e diversificar o público que trabalha, mora e consome na região (Albinati, 2017).

Esse movimento produz o risco de elitização e gentrificação de certos espaços da região portuária, o que é legitimado pelo discurso de que a pretensa revitalização da área portuária seria financiada integralmente com recursos privados e benéfica para a cidade.

Desde o início do projeto, não obstante, o contexto político e econômico sob o qual se alicerçava o Porto Maravilha sofreu transformações agudas. Em âmbito nacional, o país passou a assistir a uma forte crise políticoeconômica. A isso combinou-se a crise econômica da economia do Rio de Janeiro, em nível estadual e local, o que agravou ainda mais os efeitos da recessão experimentada pelo país. Por outro lado, a resistência do mercado imobiliário frente à capacidade de promoção da região portuária como novo bairro de classe média não apenas desestimulou o lançamento de novos empreendimentos como paralisou a venda de títulos de potencial construtivo - impondo custos ao FGTS e à execução do projeto de revitalização (Werneck, Novaes e Santos Junior, 2018).

Com efeito, em 27 de junho de 2018 a Concessionária Porto Novo lançou uma nota oficial comunicando a interrupção das suas atividades na região portuária, decorrente da indisponibilidade financeira para o pagamento da sétima etapa do contrato de PPP, que permanecia parada até a conclusão deste artigo, em agosto de 2019. 
A Operação Urbana Porto Maravilha segue em frente, sendo, pelo menos até agora integralmente financiada pelo poder público, contrariando o discurso que legitimou a parceria público-privada, de que as obras e serviços seriam financiados com recursos privados.

Para interpretar esse processo, apresentamos a discussão e os resultados da pesquisa a partir de três eixos de analise visando a compreensão das contradições que marcam a implementação deste projeto de reestruturação urbana na zona portuária: (i) a especificidade da configuração socioespacial do Rio de Janeiro expressa na sua ordem urbana híbrida, desigual e combinada, fortemente marcada pela diáspora africana; (ii) os experimentos de urbanização neoliberal no Rio de Janeiro; e (iii) a gentrificação periférica.

\section{A Ordem Urbana Híbrida, Desigual e Combinada e a Diáspora Africana}

As transformações urbanas pelas quais as cidades latinoamericana vêm atravessando nos últimos anos têm sido objeto de disputa tanto do ponto de vista prático, envolvendo os projetos de desenvolvimento urbano e regional que são implementados pelos Estados e governos das cidades, como do ponto de vista teórico-conceitual, no qual se busca explicar e interpretar as dinâmicas de desenvolvimento desigual das cidades e regiões dos países periféricos.

No contexto contemporâneo de desenvolvimento neoliberal, fortalecem-se e difundem-se correntes teóricas e políticas que têm contribuído para promover e legitimar tais transformações. Entre estas correntes, destaca-se a Nova Geografia Econômica (New Economic Geography ou NEG), que pode ser considerada como "um projeto colonizador, tanto em suas reivindicações teóricas quanto em suas aplicações práticas" (Wilson, 2011, p. 374).

Do ponto de vista da teoria crítica urbana (Brenner, 2010), por outro lado, observa-se um esforço de construção de abordagens que busquem desvelar o sentido do desenvolvimento geográfico desigual sob o capitalismo neoliberal e destacar a dinâmica específica dos países periféricos, suas consequências em termos sociais e as possibilidades de escavar alternativas de superação do projeto neoliberal e do capitalismo (Harvey, 2016).
No contexto contemporâneo, a teoria crítica urbana estaria desafiada a interpretar a proliferação de novas geografias de governança urbana, que emergem ao redor do mundo a partir dos anos 1980. O desenvolvimento geográfico desigual associado aos ciclos de industrialização anteriores vinha sendo interpretado centralmente a partir de modelos espaciais expressos por categorias tais como urbano-rural, centro-periferia, metrópole-colônia, que não seriam mais capazes de explicar as condições de existência contraditória de "riqueza e pobreza, crescimento e declínio, inclusão e exclusão, centralidade e marginalidade produzidas mutuamente em todas as escalas espaciais, do bairro ao planetário" (Brener e Schmid, 2015, p. 152).

Como argumentam Brenner e Schmid (2015, p. 151), esta nova paisagem da governança territorial e em rede seria caracterizada por ser "intensamente variegada, polarizada, multiescalar e relativamente descoordenada". É nesse cenário, que os autores colocam o desafio de desenvolver uma nova epistemologia do urbano, envolvendo novas categorias, métodos e geografias capazes de interpretar a vida urbana contemporânea.

Inspirados por essas ideias, nosso argumento é de que a compreensão das especificidades da governança territorial e da configuração urbana da América Latina, em geral, e do Rio de Janeiro em particular, pode ser ampliada com o conceito de ordem urbana, tal como formulado por Ribeiro e Santos Junior (2017), definida como os padrões de integração social e econômica, que se expressam na organização e morfologia do espaço das cidades.

Tomando como referência Polanyi (2000), os autores argumentam que a ordem urbana das cidades latinoamericanas tem como principal característica a coexistência de padrões desiguais e combinados de organização social e integração econômica. Do ponto de vista econômico, esse padrão se expressaria na realização de trocas fundadas na lógica do mercado convivendo com trocas orientadas por valores similares à reciprocidade e à redistribuição.

Ribeiro e Santos Junior, tomando como base a sociologia latino-americana, sustentam que "a rápida urbanização, associada à industrialização e à modernização, não eliminou práticas de clientelismo, corporativismo, ou patrimonialismo que ainda impregnam as esferas do mercado, sociedade e Estado" (2017, p. 3). 
Abordando o caso do Rio de Janeiro, os autores destacam que a informalidade e a ilegalidade urbana seriam a expressão de um processo complexo "resultante da industrialização no Brasil no contexto do fordismo periférico", no qual a mercantilização do trabalho teria ocorrido tanto através de mecanismos similares à acumulação primitiva de capital como da urbanização da população agrária. Neste contexto, a ilegalidade e informalidade da terra seriam "resultados de formas específicas da governança urbana e da regulação sociopolítica que sustenta o desenvolvimento do capitalismo industrial brasileiro" (2017, p. 4).

Com efeito, "a dinâmica da ordem urbana construiu-se com base em mecanismos de mercado regulados fracamente pelo governo e integrados pelas relações de reciprocidade e redistribuição através de laços sociais" (Ribeiro e Santos Junior, 2017, p. 4). No Rio de Janeiro, essas dinâmicas de reciprocidade e de redistribuição estariam entrelaçadas à lógica de mercado na conformação de uma ordem urbana híbrida, desigual e combinada. Como sustentam os autores,

Os resultados desse padrão institucional híbrido implicam três dinâmicas socioespaciais concomitantes do uso e produção do espaço residencial: primeira, a autosegregação das classes dominantes na forma de uma forte concentração voluntária em certas áreas bem-dotadas de melhor infraestrutura e serviços urbanos; segunda, a periferização das classes populares em áreas mais pobres com serviços públicos básicos inadequados e distantes dos locais de trabalho; terceira, a ocupação pelas classes populares das áreas intersticiais (por exemplo, encostas, margens de rios, terrenos ociosos públicos ou privados) em bairros de classe média e média-alta da cidade, constituindo um processo comumente referido como "favelização" (Ribeiro e Santos Junior, 2017, pp. 3-4).

A noção de ordem urbana também parece ser consistente com a teoria da ordenação espaço-temporal de Harvey (2003). Para Harvey, uma ordenação espaçotemporal reflete uma configuração ordenada/fixada espacialmente e se expressa em alguma forma física, por um determinado período de tempo relativamente longo, que seja benéfico a lógica de acumulação de capital. Por outro lado, a ideia de ordenação espaço-temporal também é utilizada pelo autor como uma metáfora para os ajustes espaços-temporais que visam responder às crises capitalistas por meio da reestruturação das configurações espaciais existentes. Essa abordagem é interessante por ressaltar a relação entre as configurações espaciais constituídas e a dinâmica de acumulação capitalista, os conflitos entre a sua permanência e possível destruição, e as novas configurações espaciais resultantes desses conflitos.

Nossa intenção é agregar mais um elemento para a compreensão da ordem urbana da cidade do rio de Janeiro: a diáspora africana e seus impactos sobre a cultura e as práticas espaciais da população afrodescendente brasileira.

A questão da diáspora africana é acionada aqui no sentido mais contemporâneo do termo. Como destacam Vassallo e Cicalo, "a ideia tem sido aplicada amplamente para descrever o processo de remoção forçada de cativos africanos durante o tráfico negreiro e a recomposição, híbrida e heterogênea, dos seus laços políticos e sociais em outros contextos geográficos" (2015, p. 22).

Apesar dos inúmeros trabalhos historiográficos e sociológicos que abordam a escravidão e a questão da integração do negro na sociedade brasileira (Fernandes, 2008) ainda parecem incipientes os trabalhos que articulam a dimensão racial à conformação da ordem urbana das cidades, como no caso do Rio de Janeiro.

A desterritorialização forçada provocada pela diáspora gera novas reterritorializações:

Os negros da África, originários da escravidão chegam aos novos territórios brasileiros, vindos de tribos distintas e ambientes diferentes [...], os quais precisaram se organizar entre si, numa "interculturalidade", propriamente dita, com dificuldades de inserção, sobretudo na língua, na alimentação, cultos religiosos e outros. (Vassallo e Cicalo, 2015, p. 69)

Nesse contexto, se configura o caráter ambivalente do cruzamento do Atlântico. Como argumentam Simas e Rufino, “...a experiência de desterro forja uma espécie de transcultura de sobrevivência. O trançar dessa rede transcultural reescreve outras perspectivas, que confrontam e rasuram as pretensões monoculturais do colonialismo" (2018, p. 50).

Para compreender esse processo, é preciso considerar "o conflito como uma lógica imperante dos contextos 
dessas produções e a negociação como forma de sociabilidade, resiliência e invenção" (Simas e Rufino, 2018, pp. 27-28). O que sugerimos aqui, é a necessidade de levar em consideração a diáspora africana e a cultura negra, bem como seus impactos sobre as práticas sociais e espaciais da população afrodescendente, para se compreender a conformação e as características da ordem urbana híbrida, desigual e combinada do Rio de Janeiro, suas contradições e conflitos. Nessa perspectiva, a favela e o cortiço, o comércio de rua, os territórios reivindicados pelos quilombolas e os terreiros, o batuque e a roda de samba, podem ser interpretados como produções espaçotemporais vinculados a esta experiência. Dessa forma, para compreender as características híbridas da nossa configuração espacial, com suas interseções e ambiguidades expressas na convivência entre proximidade física e distância social, é preciso considerar não apenas as práticas de dominação de classe, desde o período colonial até a atualidade, mas também as práticas de resistência e negociação da população afrodescendente, para além dos espaços de organização e reivindicação dos trabalhadores. Em outras palavras, a compreensão da "gramática social da desigualdade brasileira" (Souza, 2006, p. 23) precisa integrar a dimensão de classe do processo de modernidade periférica ocorrida no país, com a dimensão racial da nossa diáspora africana.

No caso do Porto Maravilha, isso significa reconhecer a historicidade dessa região. Nesta área funcionou, entre 1758 e 1831, o Mercado do Valongo, que se tornou o maior centro redistribuidor de mão de obra escrava do Brasil (Honorato, 2008). Ao mesmo tempo, a Região Portuária "pode ser considerada lócus da resistência de uma população afro-brasileira, descendente de escravos" (Passos, 2014, p. 89). Toda essa historicidade vai se refletir nos conflitos contemporâneos em torno da apropriação física e simbólica desse território. Esta ordenação urbana, com sua espaço-temporalidade afrodescendente, tem importância fundamental na compreensão das contradições e conflitos envolvendo o experimento neoliberal e as tentativas de promover a certificação periférica, temas das próximas seções.

\section{A Urbanização Neoliberal no Rio de Janeiro}

A persistência de padrões institucionais pretéritos à implantação da ordem competitiva conformou no tempo uma configuração urbana particular, resultante de um processo histórico situado e geopoliticamente localizado na periferia do sistema capitalista. Desse modo, aquilo que viria, futuramente, a ser caracterizado como urbanização neoliberal atuaria, como não poderia deixar de ser, sobre a herança política, social, espacial e também simbólica encontrada localmente para modificá-la segundo as diretrizes de um padrão neoliberal preponderante de reestruturação regulatória (Theodore, Peck y Brenner, 2009). A ordem urbana híbrida, combinada e desigual constrange, portanto, as formas possíveis de ancoragem do neoliberalismo, num processo que conjuga dependência de trajetória (path dependence) e destruição criativa, tal como discutem Theodore, Peck e Brenner (2009).

No caso do Rio de Janeiro, a execução do Porto Maravilha dialoga com experimentos internacionais de recuperação urbana de distritos centrais e waterfronts. Replicados em diversos contextos, tais experimentos enquadram-se, num plano mais geral, às práticas de construção especulativa do lugar do novo padrão de empreendedorismo urbano, disseminado a partir da década de 1980 (Harvey 2005). Na Ámerica Latina, esse fenômeno foi embalado, particularmente, pelas condicionalidades impostas pelos programas de resgates econômico e de ajuste às diretrizes do Consenso de Washington, que ainda ganhou força com a disseminação de best practices por agências multilaterais (Werneck, Novaes e Santos Junior, 2018). Como projeto, a revitalização da zona portuária do Rio de Janeiro configura-se, desse modo, como um experimento neoliberal.

Ainda assim, a mobilização da constelação de políticas neoliberais dependeria da conformação de uma coalizão de interesses capaz de movimentar as engrenagens para intensificar o uso do solo urbano e tornar a cidade, tal qual descreveram Logan e Molotch (1987), numa máquina de crescimento. Angariando empresários, empreendedores imobiliários, políticos, setores sindicais, entidades de classe, instituições culturais, enfim, todos aqueles que tenham algo a ganhar com o crescimento da cidade, seria ela a responsável, em primeira instância, por pôr em 
marcha a transformação da ordem urbana do Rio de Janeiro, confrontando criativamente um contexto institucional irregular, enfrentando as resistências locais e mediando as forças neoliberalizantes em suas múltiplas escalas para produzir uma versão particular de um fenômeno global.

Nesse cenário, a conjuntura promovida pelo ciclo recente de megaeventos esportivos ocorridos na cidade, a Copa do Mundo de Futebol, em 2014, e os Jogos Olímpicos, em 2016 - teve papel fundamental: operou, ao mesmo tempo, como elemento catalisador para as transformações urbanas e como dispositivo de articulação dos interesses reunidos em torno da intensificação do uso da terra urbana. Esse contexto favoreceu a construção de uma coalizão de forças políticas entre os três níveis de governo (municipal, estadual e federal) e grandes corporações vinculadas à obras e serviços públicos, e também criou condições favoráveis para o estabelecimento de novos acordos institucionais e projetos de reconfiguração espaciais, implementados por meio de vários experimentos neoliberais (Ribeiro e Santos Junior, 2017). A legitimidade então conferida à coalizão de poder a partir dos megaeventos esportivos permitiu um processo intensivo de desmantelamento (parcial) de regulações, disposições institucionais e acordos políticos vigentes e criação (tendencial) de novas modalidades de regulação institucional e de formas de gestão centradas no capital, com vistas a transformar o Rio de Janeiro numa plataforma de investimentos.

A legitimidade então conferida à coalizão de poder a partir dos megaeventos esportivos permitiu um processo intensivo de desmantelamento (parcial) de regulações, disposições institucionais e acordos políticos vigentes e criação (tendencial) de novas modalidades de regulação institucional e de formas de gestão centradas no capital, com vistas a transformar o Rio de Janeiro numa plataforma de investimentos.

Para a implantação do Porto Maravilha, em particular, um conjunto expressivo de inovações normativas - que envolveu a regulamentação de instrumentos urbanísticos e de institutos de parceria público-privada, a concessão de benefícios fiscais, a flexibilização de normas de uso e ocupação do solo e a edição de novas diretrizes de investimento e de alienação do fundo público - foi executado para alavancar as transformações urbanas.
Junto ao novo arcabouço jurídico, um novo corpo institucional foi projetado, no interior da Prefeitura do Rio de Janeiro, com o objetivo de promover a revitalização da zona portuária - o que se combinou, concomitantemente, à transferência de prerrogativas públicas para a órbita híbrida da chamada administração indireta com a criação da CDURP (Werneck, 2016).

Como resultado, o projeto de grande escala foi aprovado, rompendo com a série frustrada de tentativas de renovação urbana da zona portuária, que já se estendia por 30 anos. Com um plano de intervenção organizado, inicialmente, em quinze anos, o Porto Maravilha estabeleceu vultosos investimentos para transformar as infraestruturas de mobilidade, energia elétrica, telecomunicações, esgotamento sanitário e abastecimento de água, além de prever a instalação de equipamentos-âncora para reposicionar culturalmente a região na hierarquia de lugares da cidade. O objetivo declarado era, dessa maneira, converter aquela área de perfil marcadamente popular e fisionomia portuária num dinâmico vetor de expansão imobiliária para empreendimentos comerciais modernos e projetos residenciais de médio e alto padrão, atraindo, pelo menos, cem mil novos moradores.

As inovações de ordem jurídica, institucional, espacial e simbólica não erradicariam, todavia, práticas tradicionais, mais afeitas aos princípios de reciprocidade e redistribuição de que fala Polanyi (2000). Tanto em sua concepção como em sua execução, o Porto Maravilha reconstitui a relação patrimonial entre Estado e grupos empresariais - mais especificamente, as grandes empreiteiras -, capturando, por um lado, a máquina pública e o fundo público e, por outro, submetendo o espaço urbano à forma capitalista de acumulação. Mas, ao mesmo tempo, as transformações no ambiente institucional dão a ela uma nova roupagem, com impactos relevantes sobre a cidade. $\mathrm{O}$ modelo definido para o Porto Maravilha, com distribuição desigual de ônus e benefícios entre o poder público e o setor privado, é elemento dessa nova paisagem institucional. Como já destacado por Werneck:

Para os grupos econômicos que participam do arranjo institucional-financeiro do Porto Maravilha, os ganhos são assegurados por cláusulas contratuais, as quais estipulam 
cronogramas de desembolso favoráveis, critérios de desempenho de aplicação limitada e garantias públicas robustas. Mesmo aqueles que investem em empreendimentos imobiliários na área portuária, façam parte da estrutura de gestão da operação ou não, são beneficiados pela execução de toda a infraestrutura projetada para a revitalização da área portuária logo nos primeiros anos, graças aos recursos antecipados por um fundo paraestatal, o FGTS. (2016, p. 188)

Esse desenho, é claro, reflete a penetração dos interesses empresariais no Estado, bem como os elos de conexão entre atores públicos e privados. Mas dizem respeito, ao mesmo tempo, aos constrangimentos enfrentados por uma economia periférica ao tentar levantar recursos financeiros para a construção de novas infraestruturas - e, nesse sentido, a mobilização do fundo público não se configura, apenas, como estratagema político. As diretrizes neoliberais se associam à trajetória da política carioca e, ainda, às coerções determinadas pelo desenvolvimento desigual do capitalismo para promover um arranjo híbrido. Se os nexos com a financeirização não se encontram, à primeira vista, no acionamento de um mercado de capitais robusto, também é verdade que os riscos e os custos impostos de maneira desigual comprometem igualmente agentes públicos e privados às perspectivas de valorização (Werneck, 2016, p. 189). Por sua vez, a base do modelo na mais-valia urbana cria uma especulação do tipo financeirizada, que se expande do lote para trechos urbanos inteiros e se abre a novos agentes (Ferreira e Fix, 2001), à medida que o Rio de Janeiro possa se confirmar como fronteira de acumulação.

As exigências para alcançar esses objetivos implicam em transformações socioespaciais que promovem impactos sobre a configuração urbana. Numa cidade em que, por um lado, a industrialização não foi capaz de incluir toda a massa de imigrantes e os descendentes de escravizados e, por outro, a rápida urbanização levou a um alto grau de informalidade, o experimento neoliberal procura interferir sobre a dupla dinâmica de proximidade territorial e distância social que caracteriza, até então, a ordem urbana do Rio de Janeiro.

\section{A Gentrificação Periférica}

Se há forças estruturadoras globais que impulsionam e generalizam a gentrificação como uma política do urbanismo neoliberal (Smith, 2006), também existem barreiras e processos locais que caracterizam as experiências de gentrificação em cada localidade. Conforme argumenta Lees (2000), há "geografias da gentrificação", pois a influência de diferentes mercados imobiliários, política local, interesses privados e organizações sociais marcam as características que a gentrificação pode assumir, consoante ao contexto histórico-geográfico considerado.

O conceito de gentrificação passou a ser progressivamente acionado em diversos estudos sobre renovação urbana ao redor do mundo, e também no Brasil, buscando-se entender os processos de elitização dos espaços bem localizados e ocupados por classes populares, que passavam por projetos de renovação urbana (Bidou-Zachariasen, 2006).

No caso das cidades brasileiras, o conceito de gentrificação permitiu identificar que diversas experiências de elitização de territórios populares se dão em maior medida no padrão de lazer, turismo e entretenimento, do que no padrão residencial. Os projetos de renovação urbana parecem atrair novos empreendedores, em geral de fora das localidades, e uma população de classe média para consumir bens e serviços que passavam a ser ofertados, e nem tanto para estabelecer residência (Frúgoli e Seklair, 2010; Novaes, 2018; Siqueira, 2014). Além disso, em muitos casos, essas experiências de gentrificação estariam atreladas à ação direta do Estado ao direcionar investimentos públicos para determinadas áreas da cidade em detrimento de outras, modificando legislações a favor do mercado e, em alguns casos, promovendo remoções das classes populares de áreas em processo de renovação urbana (Furtado, 2014).

No entanto, nosso argumento é que mesmo a abordagem ampliada em torno da gentrificação não consegue apreender plenamente as especificidades do fenômeno no Brasil. Nesse sentido, incorporar as características da ordem urbana das cidades pode contribuir para a compreensão da multidimensionalidade desse processo que combina práticas espaciais, regulação territorial, vida cotidiana, resistências e contestações da 
população, resultando em um padrão variegado de urbanização e de desenvolvimento geográfico desigual.

No caso do Porto Maravilha, vale a pena destacar dois aspectos que caracterizam os processos de gentrificação na região: (i) a promoção da mudança no seu padrão imobiliário, seja corporativo, comercial ou residencial, o que ocorreu por meio de políticas combinadas de privatização de imóveis públicos, remoção das ocupações urbanas de imóveis abandonados e, criação de vazios urbanos atrativos para o mercado imobiliário; (ii) a mudança na representação simbólica da região portuária, envolvendo a política de patrimônio histórico-cultural e a criação de novos equipamentos culturais atrativos para a população de média e alta renda e para o mercado turístico. Apesar de todos os esforços empreendidos na elitização da área, em ambos os casos sobressaem as contradições e a reprodução da ordem urbana hibrida, desigual e combinada.

Desde o lançamento da Operação Urbana em 2009, foram privatizados 19 terrenos públicos da União, liberando vazios urbanos nas áreas de alto potencial construtivo, capazes de consumir os CEPACs (Santos Junior, Werneck, Borba e Carvalho, 2019). Neste mesmo período, foram licenciados na região portuária 77 empreendimentos (dentre novas construções e reformas de construções antigas), tais como restaurantes, bares, hotéis, shopping center, escritórios e imóveis residenciais (Werneck, Novaes e Santos Junior, 2018). O número de licenciamentos é muito baixo para quem deseja transformar a região portuária em um novo centro de negócios, turismo, lazer e moradia para classe média. E é ainda menor, em torno de 13 , o número de empreendimentos passível de consumir CEPACs, o que é incapaz de dar sustentabilidade financeira a operação urbana.

Além disso, dentre estes empreendimentos, nota-se que há o predomínio de imóveis corporativos e comerciais em relação a imóveis residenciais, o que poderia ser interpretado pela forte demanda por este tipo de imóvel no centro da cidade e pela ausência de atratividade dessa área para as classes média e alta, que teriam preferência por outros bairros. Cabe apontar também que nem todos esses empreendimentos estão em pleno funcionamento, seja porque as obras não foram concluídas, seja porque se quer elas foram iniciadas. Embora haja uma relativa estagnação imobiliária na região portuária, como já pudemos destacar em outro momento, o investimento em novos empreendimentos - sejam eles residenciais de alto padrão, corporativos ou hoteleiros - tem localização concentrada: localizam-se nas faixas de maior potencial construtivo e no entorno das novas âncoras culturais, sobretudo, o Museu do Amanhã e o Museu de Arte do Rio (Werneck, Novaes e Santos Junior, 2018).

A promoção dessas transformações socioespaciais da região portuária teve como uma das suas principais marcas a remoção de famílias residentes em imóveis informais situados nas áreas de maior potencial construtivo, de grande interesse do mercado imobiliário, e das favelas, de forma a promover uma nova representação simbólica da região. Com efeito, mais de 400 famílias foram removidas de cinco ocupações bem consolidadas na região. Soma-se a isso a remoção de cerca de 200 famílias da favela da Providência e de 30 famílias da favela Pedra Lisa (Comitê Popular da Copa e das Olimpíadas, 2015). No entanto, cabe registrar que a resistência da população da favela da Providência em aceitar sair para outras localidades, para dar lugar as obras de urbanização do morro, impediu a remoção de um número muito maior de famílias.

Por outro lado, apesar de ter sido elaborado um plano de habitação de interesse social para região, este não saiu do papel, embora tenha envolvido a articulação de diversos atores sociais como movimentos populares de luta pela moradia, prefeitura e universidades (Werneck, 2017).

Uma das barreiras para a transformação do perfil imobiliário da região portuária é a representação simbólica da região, associada ao lugar da carência, da pobreza e da marginalidade, conformando o que Wacquant (2001) denomina de estigma territorial. A região portuária é reconhecida por ser um território popular.

Por isso, além da modificação do padrão imobiliário, o experimento neoliberal também busca transformar as representações simbólicas da região portuária, um requisito para a mudança nas formas de apropriação desse espaço. Enquanto os símbolos da renovação figuram em novos empreendimentos culturais como o Museu do Amanhã, o Museu de Arte do Rio e o Boulevard Olímpico, apaga-se a marca histórica da região como 
território de ancestralidade africana, onde a questão do patrimônio histórico-cultural joga um papel central. Albinati (2017) destaca que a apropriação do patrimônio histórico-cultural da região associado a herança africana, realizou-se a partir da ideia da escravidão no tempo passado, propondo, para o presente, a apropriação de forma mercadológica da herança cultural africana. Uma forma de interpretar o projeto neoliberal de representação simbólica da região poderia ser esta: o passado foi dos negros, o futuro é dos brancos.

No entanto, enquanto o circuito oficial busca colocar no tempo passado a história da escravidão no Brasil e se apropriar de forma mercadológica da herança africana da região, a participação de grupos organizados do movimento negro e ações insurgentes da população diretamente atingida pela transformação da área portuária, tensionam essa apropriação e disputam os usos político-culturais na região. Nessa perspectiva, afirma-se as marcas afrodescendentes da região no passado, no presente e no futuro. Tendo em vista a condição econômica, a existência de uma grande área de preservação histórico-cultural, uma população de baixa e média renda, majoritariamente afrodescendente, e muitas favelas e cortiços, parece pouco provável que a região portuária sofra um amplo processo de gentrificação no padrão imobiliário, mudando profundamente seu perfil social. Assim, nossa interpretação indica que a região está diante de um processo de transformações mais complexo, que combina despossessão, expulsão das classes populares e novas formas de apropriação do espaço, embranquecimento dos símbolos culturais e da população que frequenta e consome os serviços ofertados pelos estabelecimentos comerciais, entrelaçado e convivendo com processos de permanência, resistência, afirmação da cultura afrodescendente, e insurgências, reconfigurando o conflito em torno da apropriação do espaço.

Assim, para interpretar as experiências de elitização na região portuária e nos territórios populares na cidade do Rio de Janeiro acionamos a ideia de gentrificação periférica (Novaes, 2018), pois tendo em vista as contradições indicadas anteriormente, o conceito tradicional não parece levar em conta a ordem urbana híbrida, desigual e combinada, nem os conflitos em torno da apropriação do território e de suas marcas simbólicas, em especial, o conflito em torno do embranquecimento e da afirmação da cultura afrodescendente. Nesse contexto, parece pouco provável que esses territórios populares sofram um amplo e profundo processo de gentrificação. No entanto, a opção por continuar utilizando o conceito com o adjetivo periférico quer sublinhar o processo de relativa elitização de algumas práticas e áreas na região, em decorrência da urbanização neoliberal promovida pelo poder público e pelos agentes privados, que parece reproduzir na escala micro, a condição desigual e híbrida da ordem urbana da cidade. Nesse sentido, a gentrificação periférica seria a expressão das diversas contradições, relacionadas a nossa ordem urbana híbrida, desigual e combinada, que tanto ameaçam as tentativas de apropriação desses territórios pelas elites e os processos de embranquecimento e aniquilação da cultura negra existente na região, como também ameaçam a reprodução das classes populares que vivem e dependem desse território.

\section{Conclusões}

A análise desenvolvida neste artigo possibilita enunciar a interpretação das contradições associadas à implementação do projeto de renovação do Porto Maravilha em torno de três teses.

A primeira tese (seção 2) afirma que a compreensão das transformações urbanas no Porto Maravilha deve levar em consideração as características específicas da configuração urbana da cidade - uma ordem urbana híbrida, desigual e combinada (Ribeiro e Santos Junior, 2017) -, e do papel da cultura negra e da diáspora africana na sua configuração. Essa formulação parte do princípio de que a compreensão das transformações espaciais decorrentes do desenvolvimento geográfico desigual, sob o neoliberalismo contemporâneo, exige uma nova epistemologia fundada na teoria crítica urbana (Brenner, 2010; Brenner e Schmid, 2015), capaz de levar em consideração a interação entre os processos de acumulação de capital em escala global e as características específicas da configuração espacial de cada localidade.

A segunda tese (seção 3) argumenta que o Porto Maravilha se constitui em um experimento neoliberal deflagrado por uma coalizão de interesses, mas que sua implementação é constrangida pela ordem urbana híbrida, desigual e combinada e, ao mesmo tempo, a modifica, num processo de destruição criativa 
multiescalar que produz uma versão local de um fenômeno global.

A terceira tese (seção 4) argumenta que os projetos de renovação urbana no Rio de Janeiro promovem um tipo particular de elitização, a gentrificação periférica (Novaes, 2018), caracterizada por processos de branqueamento (Lopes-Morales, 2015) e tentativas de aniquilação da cultura negra, mas as resistências sociais, ancoradas na diáspora africana, resultam na reprodução da ordem urbana híbrida, desigual e combinada.

Cabe registrar o caráter ensaístico das teses aqui enunciadas, que podem ser exploradas e aprofundadas para uma compreensão adequada das transformações urbanas contemporâneas da cidade do Rio de Janeiro. Como afirmado anteriormente, o fundamental é levar em consideração a interação entre os processos de acumulação de capital em escala global e os processos sociopolíticos específicos de cada localidade, apreendendo as modalidades específicas de neoliberalização e de desenvolvimento geográfico desigual. Nossa intenção foi contribuir nessa direção.

No caso do Porto Maravilha, baseado nas teses enunciadas no artigo, podemos dizer que é preciso levar em consideração: (i) a difusão e adoção de modelos de empreendedorismo urbano e a vinculação subordinada da cidade aos circuitos globais de capital; (ii) as características específicas da ordem urbana da Cidade do Rio de Janeiro, híbrida, desigual e combinada (Ribeiro e Santos Junior, 2017); (iii) sua historicidade, fortemente marcada pela diáspora africana e pela cultura negra; (iv) a dinâmica política das coalizões de poder; e (v) as contestações e resistências associadas a estes processos de transformação. Esse enfoque permitiu reconhecer, por exemplo, que os processos de elitização da área portuária do Rio de Janeiro se diferencia do clássico fenômeno da gentrificação nos países centrais, podendo ser denominado de gentrificação periférica, para demarcar suas contradições, e especificidades simbólicas, tais coma tentativa de branqueamento e de substituição da cultura afrodescendentes desse território popular, visando sua destinação ao consumo turístico (Lopes-Morales, 2015). Mas todo esse processo é atravessado por conflitos e disputas em torno da apropriação do território, que devem ser mais explorados analiticamente. Além disso, consideramos que é um desafio teórico e político aprofundar as contradições desse experimento neoliberal, denunciar seus perversos impactos socioespaciais e escavar alternativas ao projeto neoliberal na perspectiva da afirmação do direito à cidade [R]

\section{Referência}

Albinati, M. (2017). Cultura e planejamento urbano na Zona Portuária carioca: uma articulação utilitária. Emetropolis, 29(8), 24-31. http://emetropolis.net/artigo/218?name=cultura-eplanejamento-urbano-na-zona-portuaria-carioca

Arantes, O. (2000). Uma estratégia fatal: a cultura nas novas gestões urbanas. In Arantes, Vainer e Maricato, A Cidade do Pensamento Único: Desmanchando consensos (pp. 11-73). Petrópolis: Vozes.

Bidou-Zachariansen, C. (2006). De volta à cidade: dos processos de gentrificação às políticas de "revitalização" dos centros urbanos. São Paulo: Annablume.

Bourdieu, P., Chamboredon, J. C. e Passeron, J. C. (2004). Ofício de Sociólogo: metodologia da pesquisa na sociologia. Petrópolis: Vozes
Brenner, N. (2010). O que é teoria crítica urbana? EMetropolis, 3(1), 20-28. http://emetropolis.net/artigo/17?name=o-que-eteoria-critica-urbana

Brenner, N. \& Schmid, C. (2015). Towards a new epistemology of the urban? CITY, 19(2-3), 151-182. https://doi.org/10.1080/13604813.2015.1014712

Brenner, N. \& Theodore, N. (2002). Cities and the geographies of "actually existing neoliberalism". Antipode, 34(3), 349-379. https://doi.org/10.1002/9781444397499.ch1

Brenner, N., Peck, J. \& Theodore, N. (2009). Variegated neoliberalization: geographies, modalities, pathways. Global Networks, 10(2), 182-222. https://doi.org/10.1111/j.1471-0374.2009.00277.x 
Cardoso, I. (2013). O papel da Operação Urbana Consorciada do Porto do Rio de Janeiro na estruturação do espaço urbano: uma "máquina de crescimento urbano"? O Social em Questão, XVI(29), 69-100.

Comitê Popular da Copa e das Olimpíadas do Rio de Janeiro (2015). Megaeventos e violações dos direitos humanos no Rio de Janeiro. Rio de Janeiro: Comitê Popular da Copa e das Olimpíadas.

Diniz, N. (2013). Da emergência do imaginário da revitalização ao Porto Maravilha. Trabalho apresentado na Semana de Planejamento Urbano Rio 450 anos de desigualdade, Rio de Janeiro, Brasil.

Fernandes, F. (2008). A Integração do Negro na Sociedade de Classes. São Paulo: Globo.

Ferreira, J. W. (2003). São Paulo: o mito da cidade-global [Tese de Doutorado]. Universidade de São Paulo. http://www.fau.usp.br/depprojeto/labhab/biblioteca teses/ferreira doutorado mitocidglobal.pdf

Ferreira, J. W. e Fix, M. (2001). A urbanização e o falso milagre do Cepac. Folha de S. Paulo, São Paulo.

Frúgoli, H. e Sklair, J. (2009). O bairro da Luz em São Paulo: questões antropológicas sobre o fenômeno da gentrification. Cuadernos de Antropología Social, 30, 119-136.

Frúgoli Jr, H., \& Sklair, J. (2009). O bairro da Luz em São Paulo: questões antropológicas sobre o fenômeno da gentrification. Cuadernos de Antropología Social, (30),119-136. https://www.redalyc.org/articulo.oa?id=1809/18091 $\underline{3916007}$

Furtado, C. (2014). Intervenção do Estado e (re)estruturação urbana. Um estudo sobre gentrificação. Cadernos Metrópole, 16(32), 341-363. https://doi.org/10.1590/2236-9996.2014-3203

Harvey, D. (2003) O novo imperialismo. São Paulo: Edições Loyola.

Harvey, D. (2005). A produção capitalista do espaço. São Paulo: Annablume.

Harvey, D. (2008). O neoliberalismo: história e implicações. São Paulo: Loyola.

Harvey, D. (2016). 17 Contradições e o fim do capitalismo. São Paulo: Boitempo.
Honorato, C. (2008). Valongo: o mercado de escravos do Rio de Janeiro, 1758 a 1831 [Dissertação de Mestrado]. Universidade Federal Fluminense. http://www.historia.uff.br/stricto/teses/Dissert2008 HONORATO Claudio de Paula-S.pdf

Instituto Pereira Passos- IPP (2016). Diagnóstico para o Plano de Habitação de Interesse Social - PHIS do Porto do Rio. Rio de Janeiro: IPP.

https://www.portomaravilha.com.br/conteudo/outro s/Diagnostico PHIS\%20Porto\%20rev\%20abr2016.pdf

Lees, L. (2000). A reappraisal of gentrification: towards a geography of gentrification. Progress in Human Geography, 24(3), 389-408. https://doi.org/10.1191/030913200701540483

Logan, J. e Molotch, H. (1987). Urban Fortunes: the political economy of place. Berkeley: University of California Press.

Lopez-Morales, E. (2015). Gentrification in the Global South. City, 19(4), 564-573. https://doi.org/10.1080/13604813.2015.1051746

Miglievich-Ribeiro, A. (2014). Por uma razão decolonial Desafios ético-político-epistemológicos à cosmovisão moderna. Civitas - Revista de Ciências Sociais, 14(1), 66-80. https://doi.org/10.15448/19847289.2014.1.16181

Novaes, P. (2018). A Gentrificação Periférica na Cidade do Rio de Janeiro: um estudo sobre as favelas Babilônia, Chapéu Mangueira, Vidigal e Santa Marta [Tese e doutorado]. Universidade Federal do Rio de Janeiro, Rio de Janeiro.

Passos, F. (2014). O espetáculo dos espaços públicos: vivências e expressões culturais na Zona Portuária do Rio de Janeiro. Revista Brasileira de Estudos Urbanos e Regionais, 16(2), 81-96. https://doi.org/10.22296/2317-1529.2014v16n2p81

Pio, L. G. (2014). Cidade e Patrimônio nos Projetos Corredor Cultural e Porto Maravilha. Revista Húmus, 10, 55-65.

Polanyi, K. (2000). A grande transformação: as origens da nossa época. Rio de Janeiro: Elsevier.

Prefeitura do Rio de Janeiro. (18 de Julho de 2017). Decreto № 43.454 .

http://portomaravilha.com.br/conteudo/Quem\%20S omos/estatuto social.pdf

Ribeiro, L. C. e Santos Junior, O. (2017). Neoliberalization and mega-events: the transition of Rio de Janeiro's hybrid urban order. Journal of Urban Affairs, 39(7), 909-923. https://doi.org/10.1080/07352166.2017.1328976 
Santos Junior, O., Werneck, M., Ribeiro, B. e Lacerda, L. (2017). Invisibilidade, heterogeneidade e vulnerabilidade: os cortiços na área portuária do Rio de Janeiro. Trabalho apresentado no Encontro Nacional de Planejamento Urbano Desenvolvimento, Crise e Resistência: quais os caminhos do planejamento urbano e regional. São Paulo, Brasil.

Santos Junior, O., Werneck, M., Borba, T., e Carvalho, A. (2019). Propriedade Pública e Função Social: Reflexões a partir da destinação das terras da União na Operação Urbana Porto Maravilha. Trabalho apresentado no Encontro Nacional de Planejamento Urbano tempos em/de transformação-utopias. Natal, Brasil.

Simas, L. A. e Rufino, L. (2018). Fogo no Mato: a ciência encantada das macumbas. Rio de Janeiro: Mórula.

Smith, N. (2006). A gentrificação generalizada: de uma anomalia local à "regeneração" urbana como estratégia urbana global. In C. Bidou-Zachariasen (Org.), De volta à cidade. Dos processos de gentrificação às políticas de "revitalização" dos centros urbanos (pp. 59-87). São Paulo: Annablume.

Siqueira, M. (2014). Entre o fundamental e o contingente: dimensões da gentrificação contemporânea nas operações urbanas em São Paulo. Cadernos Metrópole, 16(32), 391-418. https://doi.org/10.1590/2236-9996.2014-3205

Souza, J. (2006). A Gramática social da desigualdade brasileira. In J. Souza (org.), A Invisibilidade da desigualdade brasileira (pp. 79-96). Belo Horizonte: Editora UFMG.
Theodore, N., Peck, J. y Brenner, N. (2009). Urbanismo neoliberal: la ciudad y el imperio de los mercado. Temas Sociales, 66, 1-11. http://www.sitiosur.cl/r.php?id=898

Vassallo, S. e Cicalo, A. (2015). Por Onde os Africanos Chegaram: o Cais do Valongo e a institucionalização da memória do tráfico negreiro na região portuária do Rio de Janeiro. Horizontes Antropológicos, 21(43), 239-271. https://doi.org/10.1590/s0104$\underline{71832015000100010}$

Wacquant, L. (2001). Os condenados da Cidade. Rio de Janeiro: Renavam; FASE.

Werneck, M. (2016). Porto Maravilha: agentes, coalizões de poder e neoliberalização no Rio de Janeiro (Dissertação mestrado). Universidade Federal do Rio de Janeiro, Rio de Janeiro.

Werneck, M. (2017). Habitação Social do Porto Maravilha: cadê? Observatório das Metrópoles. http://observatoriodasmetropoles.net.br/wp/habitac ao-social-do-porto-maravilha-cade.

Werneck, M., Novaes, P. e Santos Junior, O. (2018). A estagnação imobiliária e a crise do Porto Maravilha. Observatório das Metrópoles. http://observatoriodasmetropoles.net.br/wp/estagna cao-imobiliaria-e-crise-do-porto-maravilha/.

Wilson, J. (2011). Colonizing Space: The New Economic Geography in Theory and Practice. New Political Economy, 16(3), 373-397. 